\title{
Heavy Construction Systems Specialists, Inc. (HCSS)
}

Olivier Roche, Salisbury University, USA

Frank Shipper, Salisbury University, USA

\begin{abstract}
Heavy Construction Systems Specialists, Inc. [HCSS] designs and sells hi-tech software to the heavy/highway construction industry. The case describes a unique corporate culture that has made HCSS a business success in a highly competitive industry. The company's employees discuss in detail why they bought into the concept of employee ownership while Mike Rydin, the firm's $C E O$, explains the advantages but also the limits of this very successful business model.
\end{abstract}

Keywords: Entrepreneurship; corporate culture; governance; employee ownership

\section{INTRODUCTION}

"Never settle for being as good as you currently are"1

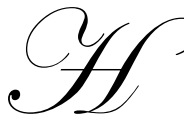

CSS was founded in 1986. For the first few years, the company's office was in the home of its founder and president, Mike Rydin. Mike had previously worked in the estimating department of a large heavy construction company where he understood, firsthand, the importance of bidding and time crunches. ${ }^{2}$ He decided to address this critical issue. Within a few years he hired his first employee, a programmer named Carl, and they created a software package, the DOS version of HeavyBid. This estimating software was made for infrastructure contractors who bid on projects ranging from $\$ 50,000$ to over one billion dollars. A key feature this young company offered was $24 / 7$ product support; this was unusual at the time. Many times calls for help came in the middle of the night and were responded to by the president himself. Today HCSS still offers 24/7 instant support, now to over 3,500 companies.

In 1989, HCSS moved into its first office building and the company has continued to expand ever since. Starting as a single-product company, HCSS's product lines currently include a half dozen other software programs. HeavyJob, for example, gives foremen the kind of information they need to manage their work responsibly and efficiently. On a daily basis, this job tracking software transforms the information collected from the construction site so that it can be used at headquarters by management. This includes time card entry on both PC and handheld devices, instant production/cost analysis, and billing and forecasting, all of which interface with the contractor's accounting software. Another example of successful software developed by the company is Equipment360, an equipment maintenance program that gives a company/customer the ability to track, identify, analyze and resolve equipment maintenance issues before a major problem occurs. This delivers cost savings to the company through less down time and fewer major equipment repairs, as well as lower fuel consumption. [A complete listing of the company's product lines is provided in Appendix 1].

Today the company has 110 employees and sales of almost $\$ 18$ million [see additional financial data in Appendix 2]. In August 2009, the company moved into its own 45,000-square-foot state-of-the-art facilities in Sugar

\footnotetext{
${ }^{1}$ This statement was made by Melissa, a business analyst at HCSS. It reflects a value that is pervasive among her colleagues. HCSS employees are confident that they are "doing the job right." At the same time, they never stop looking for better ways to do it or opportunities to use their skills to solve new problems.

${ }^{2}$ All employees are referred to in this case by their first name including the president because that is standard practice in HCSS.
} 
Land, Texas, near Houston. Mike appreciates that HCSS has come a long way from its humble beginnings, yet he considers that much remains to be accomplished; there is always room for improvement. In the case of HCSS, this company growth has happened at the same time as adjusting to a more challenging economic environment with the downturn of 2008-2009. HCSS has managed to keep its business profitable during this period, and Mike plans to resume the company expansion in 2011. The new facilities are built to accommodate twice as many employees as the company currently has. Mike is confident that HCSS has the financial resources to achieve its target growth, which is to double its activities over the next three years. While adding additional human resources has always been a challenge in this industry, HCSS has so far been very successful in attracting and retaining motivated and highly capable employees while increasing its activities at a double-digit growth rate.

\section{BUSINESS ENVIRONMENT AND STRATEGY}

HCSS operates in a highly competitive environment. In addition to large companies offering standardized software with an established brand, such as the traditional Microsoft Excel software package, there are also a host of small companies, such as "BID2WIN" or "Hard Dollar," offering customized software.

For HCSS, a smooth interaction with its customers is not only critical to increase sales but also to develop new products. Over the years, most of the ideas for new products have come out of discussion with customers. As one of the company's software development managers Minh likes to repeat to the new recruits, "Our software is developed by our customers. The customers tell us what they need and we simply deliver what they want."

While this statement is true, it is deceptively simple. The most important part of the work actually takes place between the phase of listening to what the customers want and that of delivering the right product. The next critical piece is the reliable and personable after-sale support. The company's competitive edge lies in the implementation of this inventive phase where the employees translate a customer's needs into software that meets or exceeds their requirements, at the same time maintaining high standards of work ethics and the motivation to solve customers' problems in an efficient and timely manner. No doubt, the skillful communication and good relationships between the marketing, sales, development and support departments are major factors in this seamless service delivery [see the organization chart in Appendix 3]. To achieve this level of coordination, employees have to be responsive, creative and flexible. They must be able to address customers' needs at the same time they are team players, looking beyond their own department's interests to look at those of the company as a whole. In other words, each employee has to behave like an entrepreneur developing his own business.

Minh [Manager, Software Development]: "I think it [i.e., the employee's ownership mentality] means that I need to do whatever it takes to take care of the issues that come up. Having pride in what you do and deliver. I think a reflection on the entire company is what we're delivering. How we connect with customers. How we talk to customers. Having that ownership of, 'Whatever I do does make an impact.' In my group, in particularly, I really emphasize the importance of team chemistry, teamwork; getting people involved early beyond the scope [of their regular duties]. We endorse creativity and we want that from our employees. It's not, 'Here's your job, go do it.' It 's, 'Whatever you want to do. Come to me and let me know what your ideas are.' We really foster the idea that you have and help you grow it."

At a more senior level, there is also an understanding that a corporation is a legal structure necessary to run operations and deal with other organizations. However, the company's real business and competitive advantage resides one level below. That is where the relationship between HCSS employees and the customer's employees develops and the problems of the latter are understood and resolved.

Tom [Vice President of Technical Services]: "So from an employer's standpoint, we wanted to make the kind of company that people wanted to stay at and be part of for the long term. And then from a software supplier standpoint, the thing that infuriated more customers than anything was the lack of ability to get somebody to go actually help them. The whole trend in software over the last 15 years has been to outsource your support and outsource your development. So all the parts of the software company got further and further away from their customers. The programmers just became people who wrote code, and the quality assurance personnel just became somebody who didn't really know the product, but they knew how to press the buttons to break the code. Support 
just became somebody to look through a manual and answer questions over the phone. We wanted to do just the opposite of that. So we 'reverse modeled' as an employer, but we also 'reverse modeled' as a business. We wanted to be the kind of company that our customers and our employees would have relations with and know each other."

This "employee-to-employee relationship approach" focuses on people's needs and not simply on business needs [see Appendix 4 for a description of the company's culture and its branding]. It can be illustrated by two examples of special services provided by HCSS. The first is the "Help-inar," developed by Tom (VP, Technical Services) three years ago. This concept is based on the premise that to develop a genuine relationship with potential customers, the best person to market HCSS services is not always a salesman. Tom, with a background in psychology, believes that rather than being in the business of selling services, the company is there to solve customers' problems. Since most of the actual end users of the software are the client companies' "techies," the best people to interface with them are HCSS "techies," without the interference of the sales department.

Tom [Vice President of Technical Services]: "And all a 'Help-inar' is, we take our technical people and travel them around the country and put them in a meeting room in a hotel. Customers can come in and ask them questions all day. They just get help. The end result of that is ---the customers love it. They're able to come in and get help, but then also hear about some of the other stuff that we're doing and a lot of our new products. So they become sales events, but there's no salesman there. It's only the technical people, which mean that customers hear what you're doing, but they don't hear it with a sales spin. They're hearing from an employee who's technical in nature, which they almost take that differently."

At that stage of interaction, removing the salesman from the equation allows HCSS to establish a different relationship with its customers. It also allows the company to find ideas for its new products without the filtering of the sales department.

The second service provided by HCSS is instant support. Mike considers this to be fundamental. When clients encounter technical issues with the company's software, they contact the support department; with 24-hour live support, there is no waiting. During conferences and industry fairs, end users talk to each other and share their experiences with various software providers. HCSS's responsiveness to its customers' needs is now well-established in the industry and this has contributed to the firm's rapid development to become a leader in the construction and heavy highway market.

Tom [Vice President of Technical Services]: "It always sounds kind of old and stale to say your people are your competitive advantage, but I think that it's not just the people here, it's the combination of the people without the restrictive rules that keep them from connecting with customers."

\section{HUMAN RESOURCE PRACTICES AT HCSS}

\section{Hiring the Right Employees}

HCSS uses several methods to recruit, like many other organizations in the industry. In addition to advertising on the web and in local media, candidates are recommended by former colleagues. The recruitment process has evolved over time, but it has always been very thorough, to the point where it is sometimes perceived as lengthy to a fault, especially when there is pressure to fill a critical position. Indeed, recently Mike and the senior management team were seeking to hire a marketing director to fill a role that had been open for almost a year. The most recent candidate, after six interviews, was not hired. At the same time, there were eight other more junior positions open. Mike was optimistic that they would be quickly filled with the current high unemployment rate; nevertheless, with so many people involved in the selection process, staffing an empty slot is a time-consuming endeavor. Unlike the recruitment process in many other organizations, Mike, and other senior executives are directly involved, not only for senior positions such as marketing director, but also for entry-level positions. At the midmanager level, future team members participate in the process. Between human resources' criteria and that of the functional departments, Mike is aware that there are slight differences in the traits required for the best candidates, which leads to lengthy discussions. Mike supports this "collective wisdom;" the discussions are ultimately very healthy. 
The result of this extensive process is a workforce well appreciated by HCSS clients for both its technical expertise and its diligence in solving problems. In addition, HCSS has a very low annual turnover (usually in the 2$3 \%$ range). Mike believes that time invested up front is time saved later in several ways. It avoids a situation where employees who cannot adjust to HCSS corporate culture have to be terminated and replacements hired, and it saves the training that would be required for those replacements.

Over the years, employees have joined the company for various reasons. The remuneration package is attractive, but it is not the principal factor. Indeed, in some cases, particularly at the lower levels, employees only realize how generous it is once they have experienced the profit sharing program, which may be six months to one year after they have joined. Instead, most employees quickly learn to appreciate the "intangible" advantages associated with a position at HCSS. Through the open dialogue in the lengthy interview process, candidates learn about the atmosphere in the company and its casual environment. Both parties learn about the other; in the end, both must feel that there is a good match.

Sebabi [Organizational Development Manager]: "Before I accepted the position, I asked, 'I'd like to talk to some of the employees just to find out what they really think about the company and the culture...Sophie said, 'Sure. You can come this afternoon. You can talk to anybody you want. Just walk around and pull anybody you'd like.' I was going 'What? You're not going to tell me, "Talk to this person or only that person"?' And that impressed me. And that helped me to know that it was the right decision to come here, knowing that I could talk to anybody. And I came and talked to a few people, but just that freedom to talk to any employee stood out to me."

By talking to so many potential colleagues at different levels, both the employer and candidate are able to evaluate if they have work/family values and work ethics in common. If they do, the candidate is hired.

Melissa [Business Analyst]: “That goes back to the ownership mentality that your peers are the ones you're working with every day. They probably have a really good idea whether you're going to fit into their little group or not, and how you're going to react with the different personalities in their group."

HCSS treats its employees very well but performance is expected. Even after the extremely selective interview process, in some critical and customer oriented departments, such as support, the turnover is substantial during the first 90 days of employment. For a small company operating in this industry, there is very little room for slackers or people who don't share the same work ethics and "can do" attitude.

Eric [Major Account Manager]: "Some get weeded out in those 90 days. [During the interview] they may say all the right things like, 'Oh, I'm loyal to customers. I have a good attitude. I'll go the extra mile.' Until you get them over there and let those guys [other employees in the support department] determine that, you don't really know. If you ask our customers, 'What's the biggest thing here?' it's the support, your attitude, your attitude towards support. And if someone comes in and they don't have that, they don't come close to making 90 days."

That said, past the 90-day introductory period, the voluntary turnover is only around three percent. This is very low for a company operating in this industry. In 90 days, both parties will have assessed their compatibility.

In terms of background, HCSS is quite open with regard to the profile of its employees. This reflects the diverse background of the senior management and the belief that during his/her career at HCSS, an employee will assume many responsibilities that were not anticipated when drafting the initial job description. In this way, the "can do" attitude, motivation and aptitude to learn, are as important as a degree or past experience. HCSS hires a person knowing that his/her job functions will continue to be adjusted, either because of changes in the challenges facing the company, or to adapt to the person's abilities and willingness to accept responsibilities and grow within the organization.

The recruitment process of Daniel, the receptionist and corporate ambassador, is a good example of the company's philosophy. Even the double title is illustrative. After completing a dual degree in international business and Spanish, Daniel was hired by a large US company. As he was about to finish his training program to become a manager, he decided to leave, unhappy with the corporate culture and the working conditions. Daniel decided to go 
back to school to get a Master's degree in acupuncture, but at the same time he applied for the HCSS position as a receptionist. He was interviewed by human resources, his future manager and colleagues, and finally by Mike. He was obviously overqualified for the position, but during the interview process his interest in health and wellness was discussed. One thing led to another and his job evolved, based on the qualities he offered.

Daniel [Corporate Ambassador]: "When I first started, I was asked if I would actually take on more responsibilities to help out some of the other managers [in the wellness area]. And they just thought I'd be a natural fit for it. I really enjoyed it. [After a couple of months] I realized that I needed more feedback from more people in the company, so I helped form a wellness committee, where one person from every single department is represented and they come to the meetings and we figure out where we want to go with the wellness program in the company....I'm the lowest rung of the company and yet I can go and talk to the CEO."

\section{New Employee Orientation/Acculturation Process}

At HCSS the support provided to employees during the first few months of their assignment is as important as the initial recruitment process. In a traditional orientation program, companies spend most of their time discussing matters such as benefits, health insurance, how to log into the network systems, and various company policies. These topics are also covered at HCSS, but most of the orientation program is spent discussing the history of the company, the characteristics of the industry, the interpersonal relationships within and outside the company and why these are so important for the success of HCSS.

In addition, the company has developed a mentorship program in which a new employee is paired with an experienced one from another department. The mentor acts as a "confidante" to make sure that the integration process is progressing smoothly. The new employee can feel free to discuss any personal or family issues, as well, which is why it is important that the two work in different departments.

Finally, because of the rapid expansion, senior management decided that there was a need to organize additional opportunities for a direct interface between new employees, their families and the senior management team.

Tom [Vice President of Technical Services]: "It's hard to connect with new employees now because there are usually multiple layers. So between them and myself, there are a couple different levels of supervision. They don't really work with me all the time. Between them and Mike, there's another level of supervision. So we try to do things with new employees where they get some one-on-one time with the executives at the company as a way for us to tell them what HCSS wants to be, and why we want to be that, and we're going to get there. So we have dinners that we do when we hire a new employee. Or we'll take the new employee and the spouse to dinner with the executives, and so that the new employee and the spouse both get the opportunity to meet us. And we get to meet them and just kind of break down the barriers a little bit. And we do some stuff within their orientation where they get the chance to talk to the executives at the company."

\section{Performance Review, Development and Job Promotion}

At HCSS, the collective hiring process described earlier is perceived as a logical preliminary step; the annual employee evaluations benefit from a similar 360-degree perspective. It is an anonymous review made up of two components. First, evaluators fill out a questionnaire in which each employee gets numeric grades (one to ten) for performance and ability to work as a team member, seven being considered the company average. Second, a group of peers is selected, usually including the colleagues with whom the employee interfaced the most during the preceding year. The members of this group make anonymous qualitative comments regarding the employee's performance. Then the direct supervisor discusses these comments with the employee to assess in which areas improvements are needed, as well as how to assist the employee in achieving his/her objectives. It is also a good opportunity for the employee to discuss any problem or challenges he or she faces in the organization.

At HCSS, formal titles do not mean a lot. Knowledge, people or technical skills and the ability to solve problems are the reasons an employee is sought out by colleagues or customers. To some extent, job titles are a 
reflection of these recognized abilities. In this fast-paced environment, employees are problem solvers who do not always follow the chain of command. For instance, employee $\mathrm{X}$ may report to $\mathrm{Y}$ on the organization chart but he/she will not hesitate to talk directly to Y's supervisor or another colleague of Y's in another department, if this person has the information or the ability to solve the problem at hand.

John [Software Developer]: "I do custom programming. I talk with customers about what they want, help work it up and prototype it for them, make sure this is what they want...I also help support when they have a problem, if they can't figure it out. 'Is that a bug in the system?' Or a customer is making a suggestion that needs technical input. 'Is this something that we can look at putting in?' We'll work with the product manager. 'What's coming up?' And ways we can do it. It's a pretty flexible position really, and you can make of it what you want here. I mean, we're not structured in that, 'Okay, in this role, you only do this, and in this role you only do that.' It's really, 'How much do you want to do and handle?' And so really, I think the main core ingredient at this company is problem solving."

There are several additional reasons why titles are not so important. First, employees, to some extent, "create their own job." They may have been initially hired for a specific task, but their job definition will change over time without any change in their title. As their skills improve, they may be able to spend more time solving other issues or they may discover some other tasks that they like to do or for which they have a natural talent. Second, the company and its environment change constantly. Some tasks disappear or, with experience and/or new software, take less time to complete; meanwhile, the organization faces new challenges. In this fast-changing environment, employees are task-oriented. That is why adaptability and aptitude to learn technical skills and develop people skills to be able to handle emerging challenges are so important within the organization.

Melissa [Business Analyst]: "So what I envision [in the near future] is a lot of the things I currently do now, that I've spent a lot of time on, would be made a lot more efficient, a lot more automated. And then I will look for other avenues to use my skills in the company to make another area better. Or to learn more knowledge about the software we sell. That's one of the beautiful things here is if you do a good job and you have an interest in another area, as long as you do a good job, if you want to move that route, you're more than welcome to do that. Because here we concentrate on what your strengths are [and] how can we use them better."

A final reason is efficiency and cost effectiveness. At HCSS, a good employee is an employee who is versatile and who understands the synergies that can be achieved when departments work together; someone willing to pitch in, whenever and wherever it's needed, for the good of the company as a whole. There is very little room for a "silo mentality" where an employee is only interested by the performance of his/her own department.

Genaro [Regional Manager for Technical Services]: "I've got a few roles. I help manage implementation support for our 1,200 to 1,300 companies in our West Coast region, which includes everything basically west of Texas. Recently, in the last seven or eight months, I've been assigned as the quality assurance manager for our flagship product as well, and took over that department to help kinda get some things in order. I help out with a lot of sales calls in our region, as well, and from some of the other regions, as well."

HCSS also encourages its employees to explore various interests outside the organization. For instance, expenses for employees attending ownership conferences are paid, as are those related to attending meetings of professional associations that present opportunities for development. For example, Chris (Regional Manager for Technical Services \&Training and Implementation Manager) participates at conferences as an active member of the National Utility Contractors Association where some of HCSS's existing and potential customers can be found.

HCSS grooms its own managers and rarely recruits them externally (an exception being the current search for a marketing director). However, while a promotion means facing new challenges, it does not necessarily guarantee an increase in salary or a larger office.

Chris [Regional Manager for Technical Services \& Training and Implementation Manager]: "I went from technical services to training manager to implementation manager, regional manager, product manager. These are the things that I am going after. They'll give you the opportunity, especially if you vouch for one, and you knocked it out. Then you can really move to different areas in the company but none of those [moves] dictates my salary." 
HCSS provides tuition assistance for work-related training programs at any University or College. The company also pays for off-premises seminars but primarily relies on peer-training and self-learning. Most employees are self-starters who learn new technologies and other things on their own. The organization has books they recommend, such as First Break All the Rules. ${ }^{3}$ About half of the staff has read it and participated in book studies. HCSS also offers courses in management and leadership to employees, some of which are taught by company executives. In an example of organizational development through peer interaction, the leadership team, composed of four or five senior managers, meets every month to discuss areas that need improvement. They start with basic information from the "Best Places to Work" surveys and they research what areas the employees would like to see improved in the company.

The attitude of each employee to never settle for what they already know creates a culture where everybody is constantly learning new things to ensure that they are up-to-date with their skills and their abilities to deliver high quality performance for the company. This dynamic self-perpetuates as employees recruit candidates with similar attitudes and abilities. At the same time, the organization supports new initiatives by paying for employees to go to conferences, training programs and certifications. Once these outside programs are completed, employees teach what they have learned to colleagues. HCSS tries to encourage employees to think, "How can I enhance not just my own value but also that of everybody else?"

Genaro [Regional Manager for Technical Services]: "We like to self-learn. I would say that there is some technical training that we'll go through, and get everybody; but a lot of times, it's other people who took it upon themselves first to learn and then they're teaching the rest of us. That's how we keep current with a lot of things. Somebody will go---just the interest in it so much that they figure it out, and say 'Hey. We might, as a support department, need to know about this' and then share that information with everybody else. So, it makes it---and we do send people over to do technical training. We've done that in the past, but a lot of our guys are better off just tinkering with stuff."

Overall, through the hiring, integration and promotion processes of its employees, HCSS is continuously defining and refining its corporate culture. The end result is that employees tend to be versatile in terms of their abilities and willingness to complete various tasks. They are also "problem solvers," more interested in meeting new challenges than in getting a new title and a larger office. In addition, they tend to be self-starters willing to learn and share their knowledge with other employees. Finally, as noted earlier, there is very little room for the "silo mentality." Employees are networkers who know how to reach out to other communities /departments within or outside the company.

\section{Fringe Benefits and Wellness}

HCSS provides comprehensive health care and retirement benefits. The company does not provide day care, per se, but it is very family oriented. In the case of an unexpected circumstance, employees are allowed to bring their children to the office. Often this benefits the company because employees facing emergencies do not have to call in sick; they can still work. This reduces the stress for the employee and at the same time it is another way to connect the employee's family to the work place.

As for the health and wellness of employees, HCSS does not only "talk the talk;" the organization also "walks the walk." In addition to modern workout facilities, a soccer field and a basketball court, there is also a running track on the company's premises.

Maria [Controller] “...You'll see people running the track throughout the day, taking walks around the track, and take breaks. Maybe sales will go out and walk around. I don't know if they're talking business, but they're walking around the track. It brings people together. It's kind of a team-building issue, too."

\footnotetext{
${ }^{3}$ First, Break All the Rules: What the World's Greatest Managers Do Differently, by Markus Buckingham and Curt Coffman. Simon \& Schuster, May 1999.
} 
In addition, HCSS sponsors and pays registration fees for events such as: 5-K runs, marathons and bike races. Some employees prefer indoor activities. Daniel (Corporate Ambassador), ${ }^{4}$ along with his other numerous responsibilities, organizes Pilates sessions, teaches yoga and is valued as a personal trainer. As well, he provides assistance and advice to employees during lunch breaks.

As for refreshments, company refrigerators are stocked with soft drinks, juices and Gatorade. Each week a different department is in charge of kitchen duty, restocking on a daily basis with fresh fruits and vegetables avocados, apples, oranges, grapes, carrots, strawberries or whatever is in season and healthy.

\section{Work and Family Life}

HCSS organizes picnics and Christmas parties and invites the employees' families. Beyond these formal events, many employees continue their social interactions after office hours on and off the company premises. For instance, when some employees organize a movie night, the company picks up the tab for basic food and drinks. Other employees might go to a show with colleagues and their children. Finally, HCSS tolerates "underground" activities, such as on-line video games on company's computers, as long as it is after office hours.

\section{BUILDING LEADERSHIP AND THE ENTREPRENEURIAL SPIRIT}

HCSS offers courses and training programs in management. It offers financial incentives to enhance employees' performance, but it does not stop there. Mike believes that perks and training opportunities would not fundamentally change the attitudes of the employees if it was not for the existence of three major characteristics of HCSS corporate culture: access to information, involvement in the decision-making process and tolerance for honest mistakes.

\section{Access to Information}

In this fast-changing environment, it is essential for the senior management and decision-makers to keep an "open-door policy," not just in theory but also in practice. An open-door policy does not only mean that any employee can talk to the senior management and the CEO whenever they have ideas or problems. It also means that the senior management will provide them with the information they need to accomplish their objectives without having the manager "breathing down their neck" to make sure that the job is done. Very early in the company's development, Mike realized the limits of the hierarchical structure in which a CEO tells his manager what to do, who in turn tells the employee what to do. As a company grows, the temptation to add layers of management is difficult to resist, but a bureaucratic structure is not particularly cost-effective. Instead, Mike thinks it is better to invest time recruiting the right people, give them the adequate information and let them run their business with little supervision. He decided that a flat structure in which employees assume ownership of their ideas and performance leads to a far more effective organization, particularly when these employees have been selected for their "can do" attitude and their ability to learn on their own.

Melissa [Business Analyst]: "I think that it's important for your employees to feel like they're a part of something bigger. That's a big basis for the ownership culture for me - communicating, open-book policy. It's more like you come here and you work more with family than you do, you don't just clock in and clock out. I mean you take ownership for the things you do, the things your coworkers do."

Chris [Regional Manager for Technical Services \& Training and Implementation Manager], like the receptionist Daniel, was overqualified for the position that he initially accepted at HCSS. Although he had managed about 80 franchisees in his former job, Chris started as a support technician. Within one year, his managerial skills

\footnotetext{
${ }^{4}$ At HCSS, the corporate ambassador is more than a receptionist. This person greets visitors and helps them out. It is important for clients and visitors to have a first and lasting good impression of the company. The corporate ambassador knows and remembers the names of the visitors. He is also the person employees speak to when they have logistics issues to resolve, similar to a concierge at a luxury hotel.
} 
were recognized and he was promoted to the position of training manager. As a new technician, he had a firsthand experience of the company's open-door policy.

Chris [Regional Manager for Technical Services \& Training and Implementation Manager]: “As we were working on our annual end-users meeting during which 800 to 1,000 people come to Houston to visit with us, I saw an opportunity to refine our knowledge of HCSS customer base. I said to Mark [his supervisor at that time], 'How many of our top customers show up to user group meeting?' Mark did not know the answer and he asked me to find this info and others. So, I went to our CEO and asked him. It seemed like real internal [confidential] information that you would not give a new employee... and he gave it to me... Mike always says he wants to give us the tools to do our job. So, it's very rare, very rare that you would ask for information on something that Mike wouldn't share with you.... He tells us a lot of stuff that I can promise you you'd never hear in another company if you're not on the executive level. From the biggest deals we're working on to the money we'll make out of these deals.... He will share this information with us, to make sure that we're all engaged....Because we're owners, we should know."

\section{Trusting and Involving Employees in the Decision-Making Process}

At HCSS, employees are involved in all major decisions, from hiring future colleagues to the deadline for a software release or the choice of the lay-out for their offices in the new building. One of the recent issues discussed with employees was the need to change the company's insurance provider, as well as the level of coverage that was needed. For these important deliberations, large meetings were held and everyone was invited to share their views and to help make the final decision.

Chris [Regional Manager for Technical Services \& Training and Implementation Manager]: "I remember this specifically. It was... 'If we spend this much, this is the level of service we would get.' And if we wanted to increase that, 'We can spend more to get this higher level, but it's gonna come out of our bottom line.' And at the end of the year, your share of the company's profits---and we all decided to self-insure some risks but to spend more on others because we wanted a higher level of insurance. It wasn't four or five people at the executive level saying 'This is what we're doing.' They let us decide. And that's just one example of a lot of things. So, yes, we do have a tremendous amount of trust with our executives."

Nevertheless, HCSS is a company, not a democracy. At the end of a discussion, Mike or a senior manager will make the final decision, notably when there is a stalemate or when an outcome is uncertain. Interestingly, there is less resistance from employees to implement a decision, even if they disagree with the final choice, when all options have been discussed and understood.

\section{Tolerating Honest Mistakes}

When an employee makes an honest error which is not repeated and the company tolerates it, there are benefits on two levels. First, it is very difficult for employees to take initiatives if there is zero tolerance for failure. Self-managed employees at HCSS, like managers in other companies, have to make decisions and take initiatives in a complex and fast-changing environment. A lack of tolerance stifles creativity and the entrepreneurial spirit of employees who fear negative consequences for their decisions. Second, a company's negative attitude towards failure inadvertently encourages employees to hide their mistakes as well as the consequences of their mistakes. Often, it is not the initial mistake that jeopardizes the viability of an organization but the long-term consequences of a cover-up when an employee fears sanctions.

Melissa [Business Analyst]: "I was in a test environment. I did a lot of testing to change some things. I accidentally sent out 2,000 alerts and faxes to customers telling them that they had not paid their maintenance fees. I don't know how accurate they were because we hadn't been using them in a long time. We immediately get these phones ringing off the wall; our in-boxes get filled with these replies to 'What are you talking about?' So the first thing I did was I ran to Mike [CEO] and Tom [Supervisor] and I said, 'Look, I just sent out these emails by accident and dah, dah, dah,' and I was upset. Rather than yell at me or whatever, Tom immediately sent out emails to all the same customers saying, 'We were doing some testing. We apologize for the mistake.'...At the end of the day, we did collect almost $\$ 10,000$ from clients who had not actually paid their maintenance fees and we also installed a new 
password system to avoid repeating the same mistake. Here, we accept mistakes. We expect you to learn from them and try not to make the same mistake again. But mistakes are a good way to grow and realize that something needs to be changed."

\section{CORPORATE GOVERNANCE AND THE MEANING OF "OWNERSHIP”}

\section{Governance Structure}

HCSS is an S Corporation and the company does not have to disclose any financial information to anyone. Still, they provide some data to Dun \& Bradstreet and to large customers, in order to assure the latter that HCSS is a service provider in good financial health before they sign a long-term contract to design and roll out software. HCSS also provides information on financial performance and ongoing transactions to employees so they can assess the size and likelihood of their next "profit sharing" check. For obvious reasons, the company closely guards certain critical information, such as its ownership structures and margins on certain products and services.

With regard to ownership, a few stock options were provided to employees and outsiders who were associated with the start-up during the early years of operation, as well as to a couple of external investors who financed the venture. Otherwise, the company remains essentially owned and the finances controlled by Mike and his family. Only Mike, his wife, Sophie, and Tom (VP, Technical Services) are members of the board and attend board meetings. ESOP, the Employee Stock Ownership Plan, can vote as an entity for the most important decisions, such as the eventual or hypothetical sale of the company. Employees, as individuals, do not vote their shares. Therefore, employees' ownership mentality and sense of empowerment are not only derived from share ownership through ESOP. Indeed, the impact of the share ownership program on employees' behavior is leveraged through management practices that give employees access to information and actively involve them in the decision-making process whenever the company faces key issues. Here the practical meaning of ownership is that the employees "do business" the way an owner would, and the proportional sharing of the company's profit is an integral part of that.

\section{Employee Stock Ownership Plans (ESOP)}

Within the first few years, Mike had already decided to develop the entrepreneurial mentality of the employees and to encourage their involvement in the company's affairs. Nevertheless, the decision to implement an ESOP was not an easy one. There are pros and cons for employee-owned corporations. HCSS set up a trust and made tax-deductible contributions to it. These discretionary cash contributions were initially used to buy shares from selling owners and, subsequently, shares from employees leaving HCSS or selling their shares to diversify their portfolios. The stocks acquired by the trust are allocated to the individual account of each employee based on the level of their remuneration, which also serves as the basis to compute their end of the year share of the company's profits. At HCSS, $25 \%$ of the profit sharing program is paid in shares that go to the ESOP account of each individual. All full-time employees with at least six months of service are included. The accounts vest overtime and, at HCSS, employees are fully vested after six years of service.

In addition to the tax breaks for both the owners and the employees, there are a few other advantages attached to ESOPs. First of all, participants are able to build their nest eggs for retirement while developing a sense of ownership in the company. Second, as employees build their stake in HCSS, there is an increased incentive to stay. This is particularly important in industries with high turnover rates such as the software development industry where employees typically stay an average of only 18 to 24 months with the same employer.

There are also a few disadvantages to ESOPs. First of all, employees have fewer options to diversify their portfolio. Indeed, most of the employees living in the Houston area, including HCSS employees, are painfully aware of the Enron bankruptcy. This bankruptcy ended up being particularly costly, especially for employees who had a lifetime commitment to and investment in this corporation; after the bankruptcy proceeding was closed, there was not much left for Enron retirees to live on. Second, as employees build their stake in the company and become majority shareholders, complex decisions can become difficult to make. Every shareholder has a different time frame. When long-term investments such as capital expenditures and research have a negative short-term effect on 
cash at hand and the profit sharing program, disagreements may emerge and, ultimately, the collective decision may not benefit the long-term interest of the company.

All the above scenarios were carefully considered before setting up the employees' stock ownership plans. Today, Mike still owns 33\% of the shares and the employees about 34\%. Currently, 19 employees, those who joined the company during its early years, own a majority of the $34 \%$. With the growth of the company, fewer shares were available to newcomers. As a result, over the last few years, these 19 employees were given the option to sell $10 \%$ of those shares every year. This allows the more senior employees to diversify their portfolio over time and for the company to have shares available to new employees. The balance, about one-third of the shares, is owned by the few external investors mentioned earlier who either financed the start-up or provided technical advice, such as the accountant, lawyer and programmer who accepted shares in lieu of cash as payment for their services.

\section{Stock Appreciation Rights [SARS]}

To complement the ESOPs, it was decided in 2007 to offer additional incentives and to increase the stake that each new employee had in the company. The main objective of SARS was to offer new employees, who had not benefitted from the company's fast growth as a start-up, the opportunity to benefit from future growth. This had to be achieved without offering shares, as they were not available, due to the limitations imposed on an S-Corp capital structure. Any employee who had worked more than 1,000 hours during that year was granted rights on 700 shares on the basis of the stock price at that time. At the end of the fourth year, i.e., 2011, if the stock price has appreciated, each employee will exercise those rights and pocket the difference between the initial benchmark and the value of the stock. This stock appreciation will be considered and paid out as ordinary income.

\section{End-of-Year Profit Sharing Program}

At HCSS, the profit sharing program computation is straightforward. The first $10 \%$ of the company's net profits is booked as retained earnings for the company's use. The profit sharing pool for employees represents $60 \%$ of any profits above the $10 \%$ (which, in 2007, was $\$ 1.6$ million and, in 2009, $\$ 0.9$ million). The profit sharing pool is then shared among employees, calculated on their base salary. The profit sharing program represents the same percentage of every employee's basic salary, from entry-level employees to senior executives. For 2009, which was a difficult year in the industry, the profit sharing program represented about $17 \%$ of the employee's base salary. During better years, it has sometimes reached or exceeded $35 \%$. Seventy-five percent of the profit sharing program is paid in cash and $25 \%$ in stocks that go to the employee's ESOP account.

Sebabi [Organizational Development Manager]: "And the thing that impresses me the most is that our CEO and our entire executive team do not sit there and make the assumption that, because they're at that level, they should get a disproportionately higher percentage of the profits of the company. It is still based on W-2 wages, of course, whatever your wages are. But everybody gets the same percentage. So if it's $25 \%$ for that year, then everybody gets $25 \%$ for that year. And I think that really, not only for me, personally, but for every employee, it makes them really buy into the whole concept that we're all in this together as a company, to help it to be more successful."

One advantage of the profit sharing program, particularly when the company has an established track record of treating its employees well and fairly, is that some employees accept a pay cut when they join HCSS. Others, particularly at entry level, accept salaries that would be considered low by industry standards. During the long interview process, nothing is more convincing for a candidate than to hear his/her future colleagues talking about their rewarding experience with such a system. By keeping starting salary at or slightly below industry average, the company is in a better position in the case of an economic downturn. However, the company annual raises are far above industry averages and, over time, with or without profit sharing award, an employee's income rival or exceed industry norms.

Besides motivating employees, another major advantage of the HCSS profit sharing program is that it reduces difficulties in relationships between departments with different objectives. For instance, while the sales and support departments have different priorities, employees in one area know that what is good for the other department is also good for them. 
Eric [Major Account Manager]: "They [the support department] help me on my demos all the time and you'd think maybe there'd be some animosity because they spent all this time on a sale and they're helping the salesman and the salesman is the one that ends up getting the commission. But that support guy knows that it's going to the bottom line. It's going to profit share, too."

In retrospect, Mike reflects that while the initial plan to make employees feel and behave like owners was a good idea, ESOP was probably not the best way to achieve these objectives. Indeed, over the years, ESOP triggered a few unexpected issues in the areas of tax and succession planning. In addition, as ESOP reached a certain threshold, cash payments had to be made to employees selling their shares at times when the company needed the financial resources for its expansion. Finally, ESOP was too complex for most employees to see it as a motivator to join the company and to stay during the first years of their employment.

Tom [Vice President of Technical Services]: "The ESOP is important, but it doesn't get people in the door. And it doesn't get them excited because a) people don't understand the ESOP, and b) it takes them a number of years to build enough value in the ESOP where the ESOP becomes attention-worthy."

Profit sharing programs are more palatable than other incentive mechanisms for the employees at any level and far easier to manage by the company during every phase of the business cycle. However, to make the profit sharing program even more meaningful to employees, Mike quickly understood that two additional conditions had to be met. First, the profit sharing program must be easy to understand and the allocation process transparent. Second, the amount paid must be significant and fairly allocated among employees. As noted earlier, transparency and fairness are essential to enhance teamwork within and between departments. Over the years, several employees have mentioned to Mike how many opportunities they had in their daily work to help colleagues. Any assistance provided to a colleague is a plus for the company as a whole and each employee knows that the added value generated will be fairly shared at the end of the year.

Each month a member of the senior management team leads the company lunch meeting to discuss financial performance and the ongoing transactions. However, not every employee has a financial background. Therefore, discussions about financials are usually limited to a basic review of the income statement. From the employee's point of view, the main interest is that he/she can estimate in real time the size that the profit sharing pool will attain by the end of the year. In addition, making employees aware of the financial situation by the company directly, as opposed to hearing through the rumor mill, is preferable, especially in a time of financial difficulty. Finally, when efforts such as pay cuts and/or reduced hours are needed during an economic downturn, employees are able to put the request for sacrifice within the current business context. Financial pain is more bearable when it is understood and spread evenly.

Maria [Controller]: "Every week we meet at the company lunch meetings with employees and we discuss various things going on in the company. It's very open. Everybody knows what's going on, what's going on with our products, what's new, what's different, et cetera. Some people go off, visit customers. They'll come back and tell us how that went, what they did, everything like that. But once a month, we will go over the financials.... We look at sales. Sale figures, why they might have gone up or down. They'll ask, 'Why is electricity so high this month?'...Pretty much anything. Then we look at our margins and see where they are."

\section{MOVING FORWARD: EXPANDING WHILE KEEPING A COMPETITIVE EDGE}

HCSS is conservatively managed, but well managed. The company has remained profitable even during the economic downturn and, except for the recent acquisition of their new headquarters, the company has managed to finance its activities out of its own cash flow. Therefore, to finance future rapid growth, both internal and external financial resources are available.

One issue Mike has faced since the beginning is the pace of company growth. While subject to market conditions, an unlisted, family-controlled company has no real obligation to grow rapidly. To contrast HCSS with publicly listed companies, at HCSS there is no analyst's meeting at the end of every quarter during which so-called experts, who often do not know much about the industry, pressure for "growth," "upside potential" and "market 
momentum." Neither are there venture capitalists and institutional investors on the board of the company pushing for a strategy that would deliver a rapid growth in sales and profits in the medium term at the expense of the longterm viability of the company. Mike is not under these pressures. Therefore, one option is to simply maintain the same pace. It took 25 years for Mike to grow the company to its current level and it could take another 25 years to double its size.

But is it so simple? The company has come a long way since its humble beginnings and Mike did not spend half of his life growing HCSS to let it stagnate at its current level. Besides, the company always has new products in its pipeline and in this fast-changing environment, not taking advantage of market opportunities could be very costly in the long term. In this industry, competitors do not sit idle. In fact, HCSS is about to launch a new safety software product with applications not only for companies in the construction industry where most of HCSS's current customers operate, but also for other industries, especially the large manufacturing segment. This new software offers tremendous growth potential and the opportunity to create real value not only to clients but to employees and shareholders, as well. However, introduction of this new software to a larger market requires the company to grow rapidly to get and keep the first mover advantage.

Could the company double in size over the next three years without destroying its culture and its competitive advantage? Mike recalls that even during the downturn, he still had six or seven entry-level positions open and unfilled. Quite a few applications were received but candidates rarely made it from HR to the department interested in hiring additional employees. In addition to the lengthy recruiting process, for more senior positions, there are other issues.

For instance, considering its current corporate and governance structure, would it be possible for HCSS to attract and motivate the outside talent needed to complement the company's pool of internal managers? If so, what kind of incentive package would motivate these new senior executives to make the organization more efficient without destroying its unique corporate culture?

The company is currently headed by three senior managers: Mike with a background in philosophy, Tom with a background in psychology and Steve with an MBA. It is this unusual mix of creativity and pragmatism, coupled with the fact that none of them are fundamentally money-driven, that made the company a success. Would a "hired gun" take the same pride in growing the business?

In recent years, leaders have been selected internally but Mike is aware of the limitations this creates. As the company grows rapidly, HCSS could find itself led by managers and directors who do not have prior leadership experience. And in fact, the grooming process is time consuming. Situations can also arise where the company does not have internal candidates available. Hiring outsiders is always possible, but it is not an easy process, either. If anything, the ongoing search for a marketing director has proven frustrating and time consuming, considering the number of people involved in the process. Yet the collective wisdom attached to the current selection process has been key to hiring high-quality employees who quickly adjust to the company's corporate culture.

In addition to the human resources issues, both at entry and more senior levels, there are also issues related to the communication flows between departments. Being close to the customer and being very responsive to their needs means that the channels of communication have to remain highly effective. In this regard, is the current corporate structure adequate? Mike is aware of areas that need improvement. The support, implementation and programming departments communicate well together, but the marketing, sales and programming interface is not as effective. Can the company double its size while keeping the same structure?

Even at its current size, communication has become an issue, both horizontally and vertically. Often Mike spots disconnects between the outcome of a discussion of the senior team members and the perception and understanding of this decision by the employees at more junior levels; sometimes the message becomes confused. Mike was adamant that the open-door policy was the best way to communicate directly with everyone but he wonders if this strategy will be sustainable with 200 employees when it is already difficult to succeed with 100 . 
Mike knows that he must deal with these issues rather sooner than later. In a recent meeting with Chris, he noticed that employees in the customer support department were putting in long hours, even during the economic downturn. While there is nothing wrong with long hours over a short period of time, with business picking up, there is a risk that the situation would lead to the burnout of a few key employees. And in a business that relies heavily on employees' creativity and dedication to customers' needs, this situation cannot be left unattended for long without some unpleasant consequences that would be preferable to avoid.

\section{AUTHOR INFORMATION}

Dr. Olivier Roche is an assistant professor of management and international business at Salisbury University and associate academic director of the Directors Education Program [DEP] at the McGill University Executive Institute. Dr. Roche is the author of "Corporate Governance \& Organization Life Cycle" published by Cambria Press in 2009. Prior to his academic career, Dr. Roche was an investment officer at the World Bank in Washington DC, and Tokyo. In addition to his $\mathrm{PhD}$ in management from McGill University, he is also a graduate of Georgetown Law School and is a licensed attorney who has been admitted to the bar in the state of New York.

Dr. Frank Shipper (Ph.D. Utah) is Professor of Management and Chair of Management and Marketing in the Franklin P. Perdue School of Business at Salisbury University. His current teaching, consulting, and research interests are managerial/leadership skills development, and employee ownership and culture. His articles have appeared in the Academy of Management Journal, Organizational Dynamics, Leadership Quarterly, Human Relations, Academy of Management Learning \& Education, and others. He has been recognized by the Academy of Management and the Center for Creative Leadership for his work on management development. As a consultant, he assists organizations in developing and validating their management development processes. 


\section{APPENDIX 1}

\section{Product Lines [Extracted from HCSS Website]}

HEAVYBID: HeavyBid is a powerful construction estimating software for infrastructure contractors bidding projects ranging from $\$ 50,000$ to over one billion dollars.

HEAVYJOB: HeavyJob is complete job tracking software that transforms job site information into valuable management information on a daily basis. It includes time card entry on both PCs and handheld devices, instant production/cost analysis, billing, forecasting and interfaces to the customer's accounting software,

DISPATCHER: The Dispatcher is a resource management software. It allows a company to track the usage of its equipment, tools, materials and crews and to get the most out of them. It allows a company to plan, analyze, and improve usage of these resources.

EQUIPMENT360: An equipment maintenance program that delivers cost savings to customers through lower down times, less major repairs, lower fuel consumption, and greater availability of its equipment. In essence, Equipment360 gives the customer the ability to track, identify, analyze and resolve equipment maintenance issues before they become a problem.

BIDHISTORY.COM: This is a collection of historical bid pricing and bid tabs compiled from public DOT sites throughout the United States. The benefits of using Bidhistory.com include tracking and reviewing historical bid pricing tabulations and viewing historical average prices for specific bid items.

SAFETY: A safety management software that helps a company to capture daily activities and incidents in the field, manage data in the office and deliver reportables to the management team.

VECTR GPS: Integration with the Dispatcher brings customers total control over the fleet of vehicles. It allows customers to make better decisions based on real information coming directly from the field. HCSS provides allinclusive packages that include the GPS hardware units, data service coverage and integration with the Dispatcher.

FUELERPLUS: This is a fuel management software that allows a company to easily track the amount of fuel and other fluids being dispensed into equipment and fuel trucks. It captures all the activities of a fueler, automates the flow of this data to other systems such as other HCSS applications and other accounting systems. It also allows the company to generate reports to help managers realize the true cost of fuel as well as the fueler's activities. 


\section{APPENDIX 2}

Financials

$\begin{array}{llll}\text { [In US\$] } & \underline{\mathbf{2 0 0 7}} & \underline{\mathbf{2 0 0 8}} & \underline{\mathbf{2 0 0 9}} \\ \text { Current Assets } & 9,213,653 & 6,491,900 & 7,264,040 \\ \text { Current Liabilities } & 4,216,079 & 5,650,387 & 6,146,784 \\ \text { Sales } & 17,494,651 & 19,288,557 & 17,867,967 \\ \text { Long-Term } & - & - & 6,294,179 \\ \text { Liabilities } & -2,986,656 & 2,458,502 & 1,733,857 \\ \text { Net Profit (Loss) } & 2,962\end{array}$

Note: The long-term debt of $\$ 6.3$ million was incurred to finance the construction of the new building which can accommodate 230 employees. 
APPENDIX 3

Organization Chart

\section{HCSS Department Org. Chart}

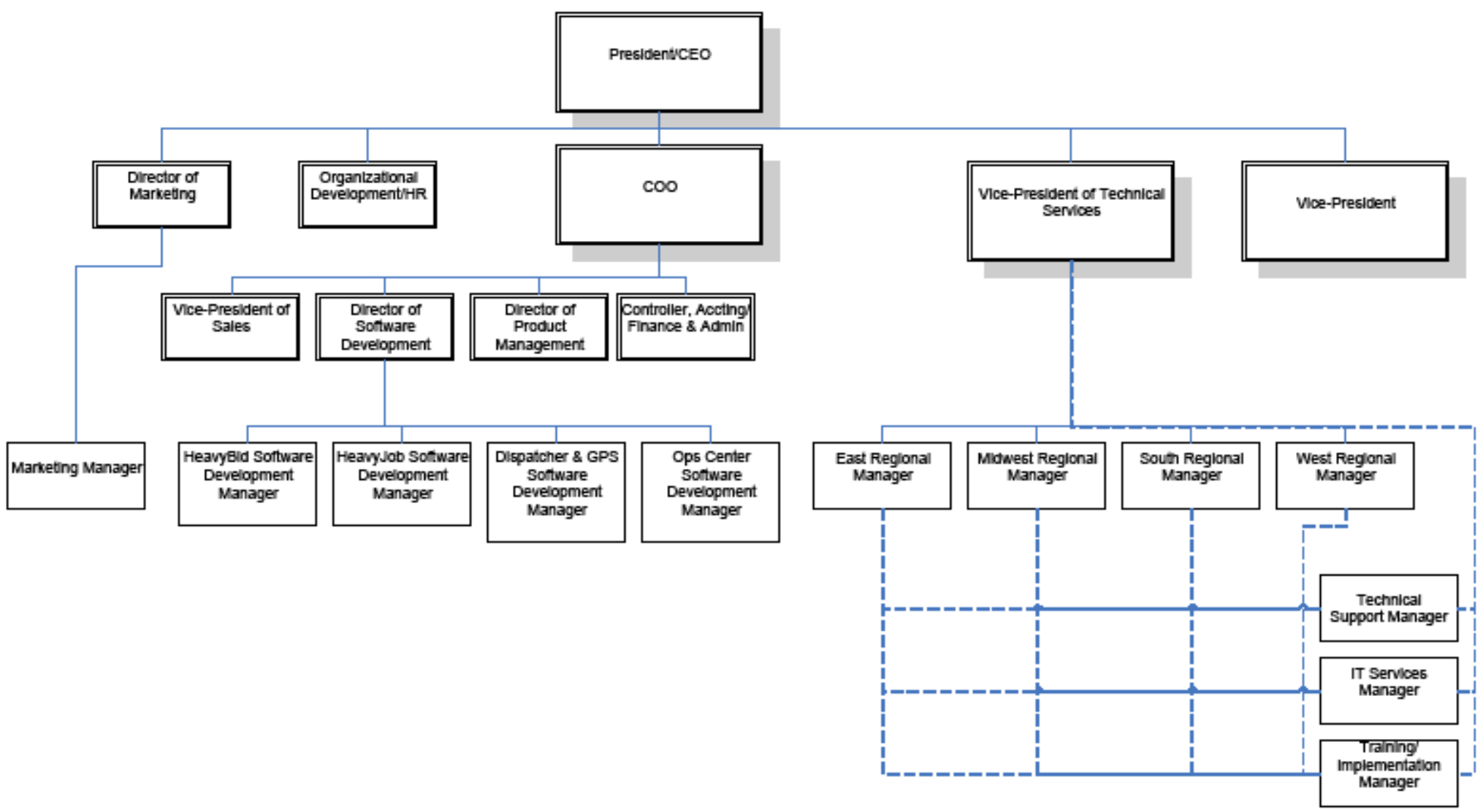




\section{APPENDIX 4}

Lessons Learned about Building An Employment Brand [Extract from keynote speech handout: "Your Culture Defines Your Brand" by Sebabi Leballo, Organizational Development Manager]

Don't waste time trying to fabricate an employer brand: You've already got a brand; your company's culture already defines your employer brand.

Use your culture to define your brand: You don't have to be a nationally known billion-dollar company in order to have a good employer brand. Build your brand around your culture and the people you hire will fit, excel and stay.

Recruiters should become marketers: Recruiters must become expert marketers and champions of the company culture and brand.

Don't hide your culture: The culture of your company is already known to applicants from the moment they walk into your office or interact with the employees that work at your company. An authentic brand will build a better pipeline of applicants.

Hire people who fit your culture: The biggest mistake you can make is to hire someone who does not fit the culture.

Make your brand toxic for the wrong people: Showcase your culture to make it toxic for the wrong people and appealing to the right people. You will inevitably find the right people and the right people will find you.

Use multiple tools to promote your brand: Increase your brand recognition using social media, videos, dedicated websites and job board branding.

Celebrate those who live the culture: Let your employees live up to their full potential and promote them to others as a great example.

Prove you have a great culture: Compete in "best companies to work for" contests to get feedback and gain credibility and recognition for your culture, which helps enhance your brand.

Executives must genuinely desire employees to have a great life: If the goals of helping employees live up to their full potential is solely driven by revenue/profit goals, your culture and brand will never flourish. 